\title{
PERANCANGAN SISTEM APLIKASI REKAPITULASI PERJALANAN DINAS PADA DIREKTORAT JENDERAL MIGAS
}

\author{
Septrianingsih Nur Fadillah ${ }^{1}$, Mei Lestari ${ }^{2}$ \\ ${ }^{1,2}$ Universitas Indraprasta PGRI \\ Jl. Raya Tengah No. 80, Kel. Gedong, Kec. Pasar Rebo, Jakarta Timur 13760, Jakarta

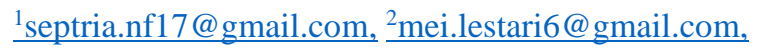

\begin{abstract}
ABSTRAK
Direktorat Jenderal Migas merupakan instansi pemerintahan di bawah Kementerian Energi dan Sumber Daya Mineral. Dalam sebuah instansi, rekapitulasi merupakan hal yang sangat dibutuhkan untuk membuat laporan akhir. Pada Direktorat Jenderal Migas salah satunya berupa rekapitulasi perjalanan dinas yang pencatatannya masih menggunakan Microsoft Excel. Penelitian ini bertujuan untuk merancang dan menerapkan suatu sistem aplikasi rekapitulasi perjalanan dinas pegawai agar dapat data tersusun dengan cepat, tepat dan akurat dalam proses rekapitulasinya. Metodologi penelitian yang digunakan adalah metode Research and Development dengan beberapa tahapan dimana untuk pengambilan data melalui pengamatan langsung, wawancara dengan pihak terkait, serta melakukan studi pustaka untuk mendapatkan informasi yang dibutuhkan. Hasil dari penelitian ini berupa perangkat aplikasi desktop yang dibuat dengan NetBeans IDE 8.2 bahasa pemrograman Java serta penyimpanan data menggunakan basis data MySQL. Pembangunan sistem ini dibantu dengan alat perancang sistem yaitu Diagram Alir Data (DAD) Konteks dan Diagram Nol. Sistem aplikasi yang dirancang ini dapat mempermudah staf pengadministrasi setiap unit dalam proses rekapitulasi perjalanan dinas pegawai pada Direktorat Jenderal Migas.
\end{abstract}

Kata Kunci: Rekapitulasi, Perjalanan Dinas, Java, MySQL, Sistem Aplikasi.

\begin{abstract}
Directorate General of Oil and Gas is a government agency under the Ministry of Energy and Mineral Resources. In an agency, recapitulation is something that is needed to make a final report. At Directorate General of Oil and Gas, one of them is in the form of recapitulation of official trips whose records are still using Microsoft Excel. This study aims to design and implement an application system for recapitulation of official travel for employees so that data can be arranged quickly, precisely and accurately in the recapitulation process. The research methodology used is the Research and Development method with several stages in which the data is collected through direct observation, interviews with related parties, and conducting a literature study to obtain the required information. The result of this research is a desktop application device made with NetBeans IDE 8.2 Java programming language and data storage using MySQL database. The development of this system is assisted by system designer tools, namely Context Data Flow Diagrams (DFD) and Zero Diagrams. This application system designed can facilitate the administrative staff of each unit in the process of recapitulation of official travel for employees at Directorate General of Oil and Gas.
\end{abstract}

Key Word: Recapitulation, Official Travel, Java, MySQL, Application System.

\section{PENDAHULUAN}

Dalam sebuah instansi, rekapitulasi sangat dibutuhkan untuk membuat laporan akhir. Rekapitulasi pada sebuah instansi yaitu dapat berupa rekapitulasi tagihan per unit, rekapitulasi pengadaan barang dan jasa, rekapitulasi perjalanan dinas, dan lainnya.

Pengadministrasian pada Direktorat Jenderal Migas salah satunya berupa rekapitulasi perjalanan dinas. Dimana perjalanan dinas memerlukan rekapitulasi yang akan dilaporkan hasil akhirnya ke bagian keuangan di Direktorat Jenderal Migas untuk mengetahui realisasi anggaran setiap tahunnya. Rekapitulasi perjalanan dinas pada Direktorat Jenderal Migas terbagi menjadi 26 unit yang masing-masing dikerjakan saat sudah akhir tahun, sedangkan perjalanan dinas pada masing-masing unit banyak jumlahnya dan hanya dikerjakan dalam waktu kurang lebih seminggu. Rekapitulasi yang banyak dan hanya dikerjakan dalam waktu sedikit membuat kurang telitinya pendataan dan hasil laporan yang tidak sesuai dengan realisasi penagihan ke bagian keuangan.

Dengan berbagai permasalahan yang ada serta seiring berkembangnya teknologi dan sistem 
informasi pada sebuah instansi terutama pada Direktorat Jenderal Migas. Hal tersebut dapat diwujudkan dengan pemanfaatan komputer yang mampu menyimpan dan mengelola berbagai macam data.

Berdasarkan penjabaran sebelumnya yang telah disebutkan, penulis tertarik membuat suatu perancangan aplikasi untuk membantu pihak Direktorat Jenderal Migas dalam menangani rekapitulasi perjalanan dinas agar data tersusun dengan cepat, tepat, dan akurat sesuai yang diharapkan, dengan judul Perancangan Sistem Aplikasi Rekapitulasi Perjalanan Dinas pada Direktorat Jenderal Migas.

Tujuan yang hendak dicapai pada penelitian ini untuk memberikan solusi dalam menangani administrasi rekapitulasi perjalanan dinas agar tercapainya kesesuaian data yang cepat, rapi, tepat, dan akurat. Serta mengusulkan pemanfaatan komputer dengan lebih maksimal.

Perancangan merupakan proses pertama pada pengembangan rekayasa produk atau sistem. Perancangan adalah dimana proses penerapan berbagai teknik dan prinsip dengan tujuan untuk menyimpulkan secara rinci sebuah alat, satu proses, atau satu sistem yang memungkinkan dilakukan realisasi fisik. (Nadeak, dkk., 2016)

Pendapat atas Djekky R. Djoht mengatakan bahwa "Sistem adalah seperangkat atau sekelompok objek yang digabungkan oleh beberapa bentuk interaksi yang tetap atau saling tergantung, kelompok unit yang berbeda, dan dikumpulkan dengan sempurna oleh alam atau oleh seni sehingga membentuk satu kesatuan yang lengkap dengan integritas yang berfungsi, bekerja atau bergerak". (Nugroho, 2017)

Perancangan sistem yaitu pemodelan konkret berdasarkan hasil analisis sistem yang sedang berjalan guna merancang database sistem maupun aplikasi/program dan mengusulkan hasil model baru. (Hamdani, 2015)

Langkah-langkah perancangan sistem yaitu dengan Physical System, Logical Model, Kamus Data, ERD (Entity Relationship
Diagram), Bagan Terstruktur, dan Normalisasi.

Aplikasi adalah perangkat lunak yang dibuat oleh suatu perusahaan komputer untuk melakukan tugas tertentu, contohnya Microsoft Word dan Microsoft Excel. (Asropudin, 2013)

Rekapitulasi perjalanan dinas yang ada pada Direktorat Jenderal Migas biasanya dimintai pada akhir tahun, dimana data tersebut akan disetorkan ke bagian keuangan sebagai rekapitulasi anggaran per tahun. Tetapi sering kali terjadi perubahan format rekapitulasi yang tidak segera diketahui setiap unit. Sebagai contoh di tahun 2019 dan 2018 lalu, permintaan rekapitulasi perjalanan dinas mengalami perubahan format.

\section{METODE PENELITIAN}

Penelitian dimulai dari bulan Maret 2021 sampai dengan bulan Juni 2021 bertempat di Gedung Ibnu Sutowo, Jalan HR Rasuna Said Kav. B-5, Jakarta Selatan 12910.

Metode penelitian yang dilakukan penulis pada penelitian ini adalah metode penelitian Research and Development (R\&D). R\&D merupakan metode penelitian yang digunakan untuk menghasilkan produk atau sistem tertentu serta menguji keefektifan produk atau sistem tersebut. (Sugiyono, 2016)

Langkah-langkah penelitian yang dilakukan yaitu dengan beberapa tahapan, berupa:

1. Penelitian dan Pengumpulan Data

2. Perencanaan Penelitian

3. Pengembangan Desain

4. Uji Coba

5. Revisi Hasil Uji Coba

6. Uji Kelayakan

7. Revisi Hasil Akhir

8. Implementasi Hasil

\section{HASIL DAN PEMBAHASAN}

Berdasarkan permasalahan sebelumnya yang terjadi, peneliti memberikan alternatif penyelesaian masalah, diantaranya:

1. Sistem rekapitulasi perjalanan dinas pada setiap unit di Direktorat Jenderal Migas yang terkomputerisasi dengan sistem komputer dan keakuratan data akan terjamin. 
2. Membuat rancangan sistem yang memiliki database sebagai sistem penyimpanan dan pengolahan data sehingga dapat terjamin keamanannya.

3. Merancang sistem pengolahan data yang terkomputerisasi agar data saling terhubung serta sudah terdapat format tetap sehingga memudahkan dalam penyusunan laporan.

\section{Diagram Konteks Sistem}

Diagram konteks adalah diagram yang mencakup proses dan memvisualisasikan ruang lingkup sistem. (Wijaya, 2016)

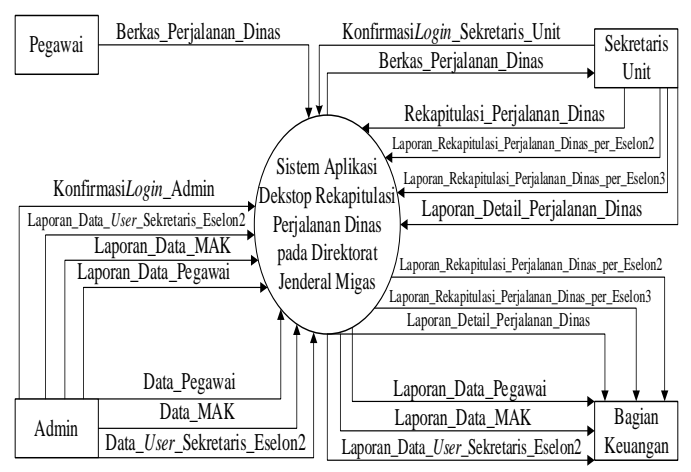

\section{Gambar2. Diagram Konteks Sistem}

\section{Diagram Nol Sistem}

Diagram nol berfungsi untuk memberikan gambaran lengkap dari sistem yang diusulkan dengan tujuan merincikan sistem menjadi proses. (Andraswari \& Sunoto, 2020)

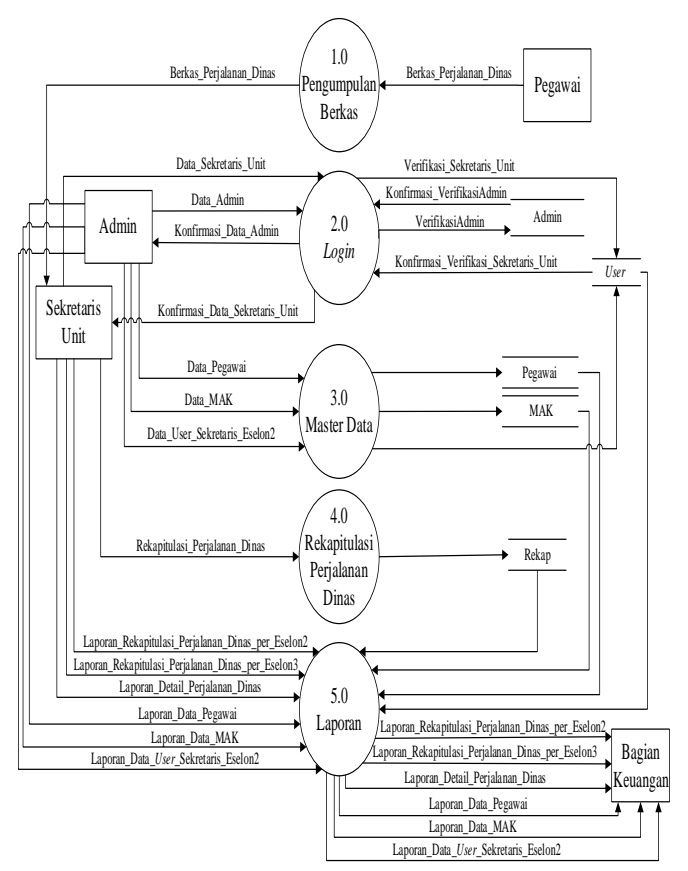

\section{Entity Relationship Diagram (ERD)}

ERD menjadi salah satu pemodelan data konseptual yang paling sering digunakan dalam proses pengembangan basis data bertipe relasional. (Lubis, 2016)

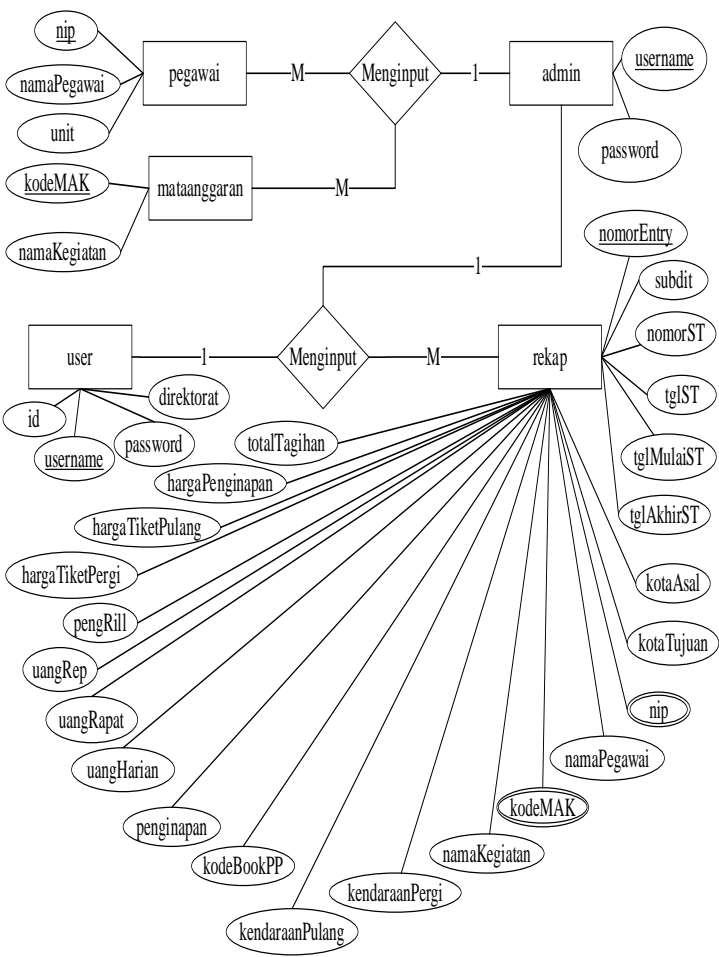

Gambar3. ERD

\section{Normalisasi}

Normalisasi adalah alat yang digunakan untuk melakukan pengelompokan pada tabel yang menunjukkan entitas dan hubungannya. (Fathansyah, 2012)

1. Normalisasi Bentuk ke-1 (1NF)

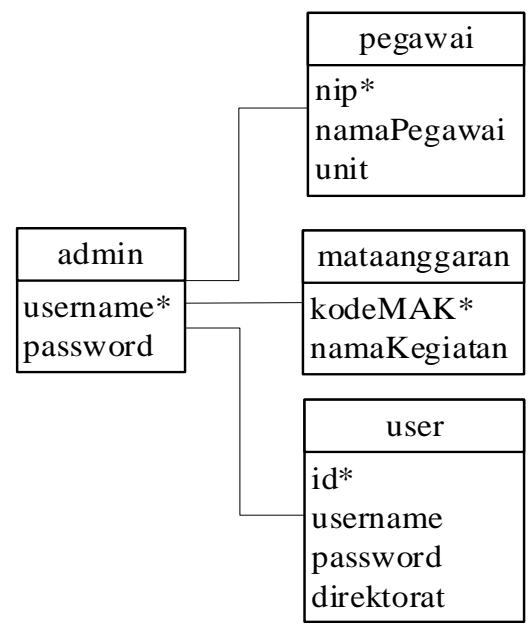

Gambar4. Normalisasi Bentuk ke-1 (1NF)

Gambar2. Diagram Nol Sistem 
2. Normalisasi Bentuk ke-2 (2NF)

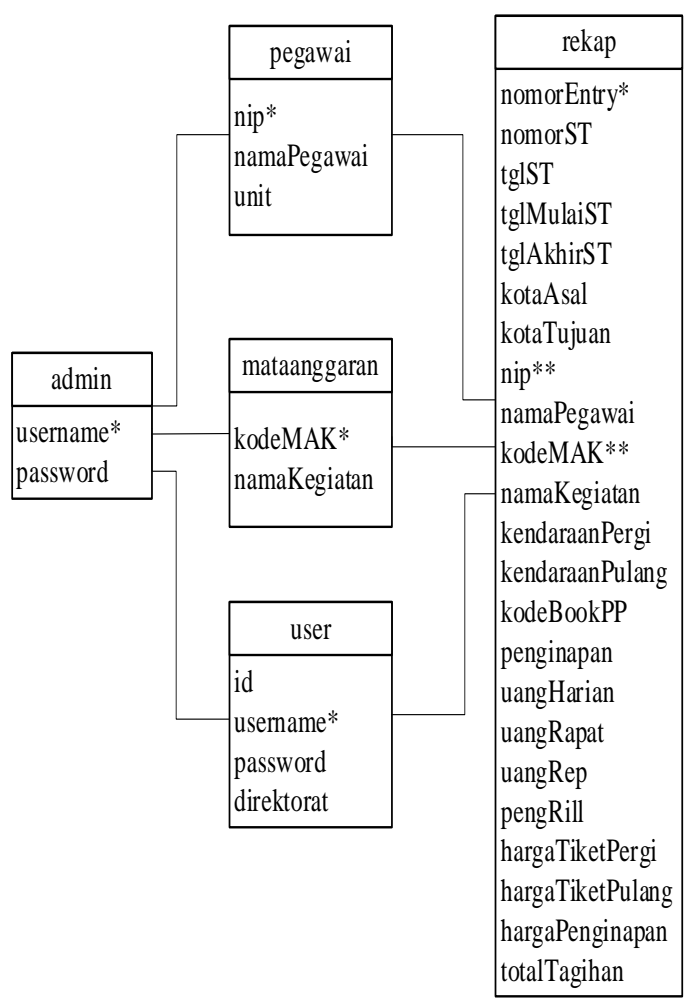

Gambar5. Normalisasi Bentuk ke-2 (2NF)

\section{Tampilan Layar Sistem Aplikasi}

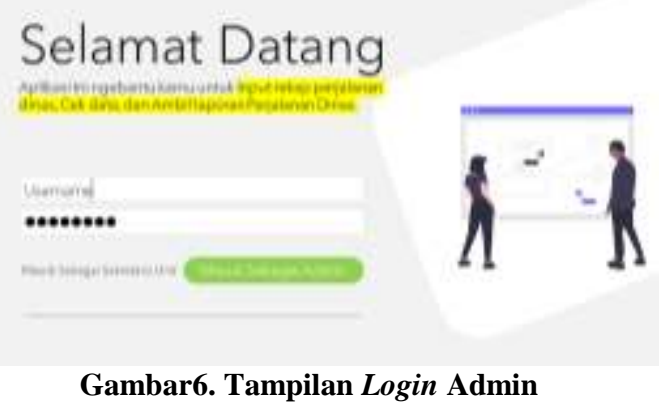

Gambar 6 merupakan login admin yang digunakan sebelum memasuki menu utama dimana agar hanya orang tertentu yang terdaftar pada database.

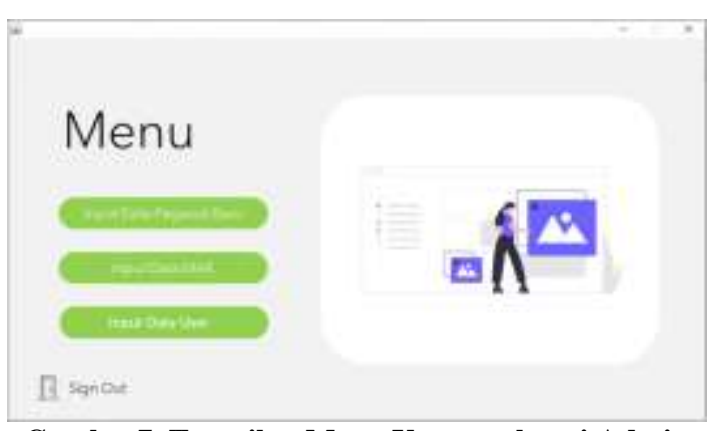

Gambar7. Tampilan Menu Utama sebagai Admin
Pada tampilan menu utama admin yaitu terdapat pilihan menu berupa input data pegawai baru, input data MAK dan input data user, sedangkan pada menu sign out terdapat perintah untuk keluar dari menu utama dan kembali pada menu login.

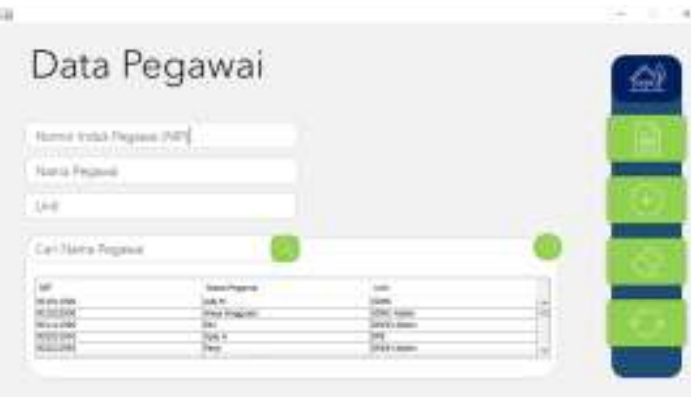

Gambar8. Tampilan Input Data Pegawai Baru

Gambar 8 merupakan input data pegawai baru untuk mencari, menambah, mengubah, dan menghapus data pegawai. Sedangkan tombol home untuk kembali ke menu utama.

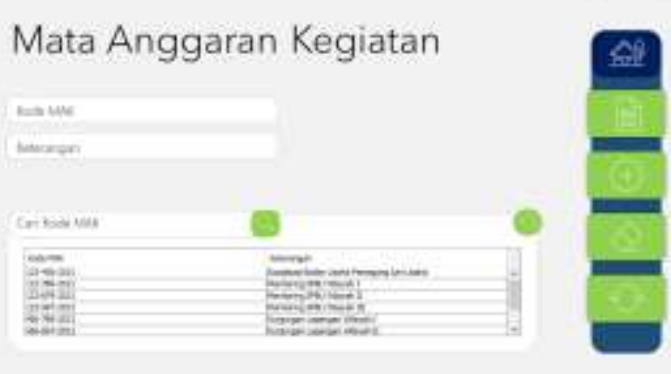

Gambar9. Tampilan Input Data MAK

Gambar 9 merupakan input data MAK untuk mencari, menambah, mengubah, dan menghapus data MAK. Sedangkan tombol home untuk kembali ke menu utama.

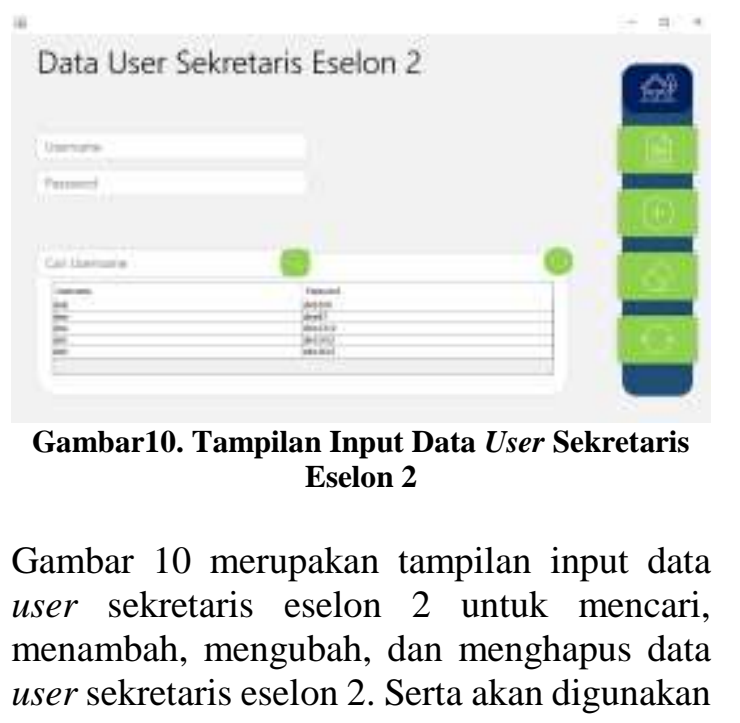


pada login sebagai sekretaris unit untuk menginput data rekapitulasi perjalanan dinas. Sedangkan tombol home untuk kembali ke menu utama.

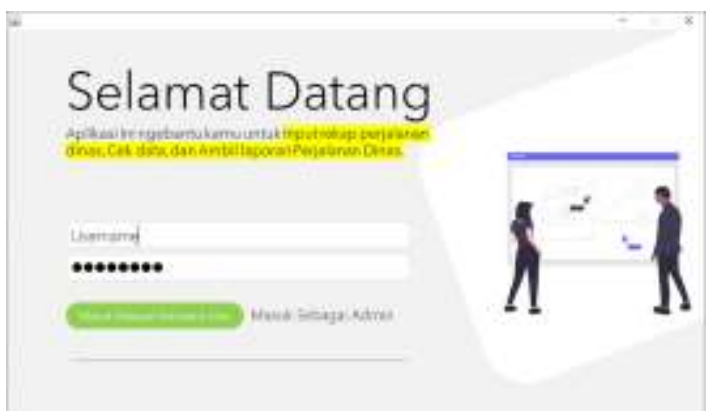

Gambar11. Tampilan Login Sekretaris Unit

Gambar 11 merupakan login sekretaris unit yang digunakan sebelum memasuki menu, agar hanya orang tertentu yang terdaftar sesuai database user sekretaris eselon 2.

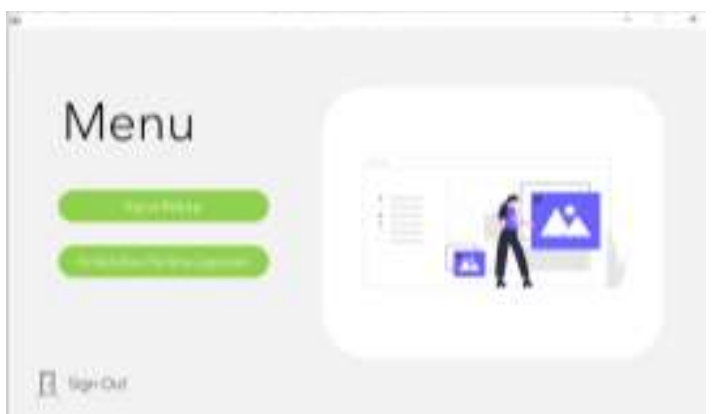

Gambar12. Tampilan Menu sebagai Sekretaris Unit

Pada tampilan menu sebagai sekretaris unit terdapat pilihan input rekap serta ambil dan periksa laporan. Menu input rekap berisikan isian dan data rekapitulasi perjalanan dinas per eselon 3, kemudian pada tombol ambil dan periksa laporan untuk mencetak rekapitulasi perjalanan dinas per eselon 2 , sedangkan pada menu sign out terdapat perintah kembali ke menu login.

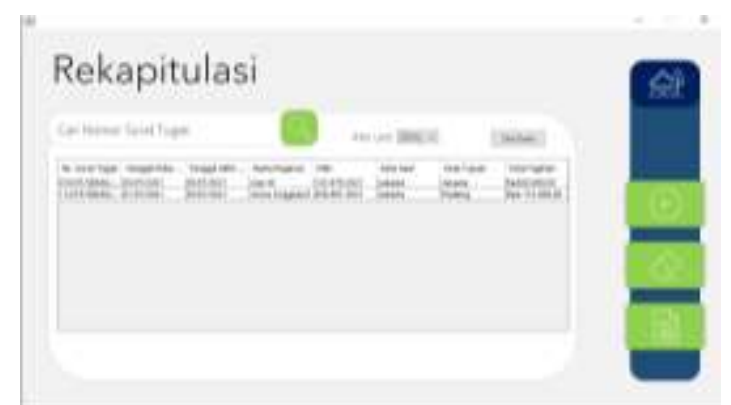

Gambar13. Tampilan Input Rekap

Pada tampilan input rekap untuk mencari, menambah, menghapus, dan mencetak data rekapitulasi perjalanan dinas serta cek detail perjalanan dinas pegawai. Sedangkan tombol home untuk kembali ke menu.

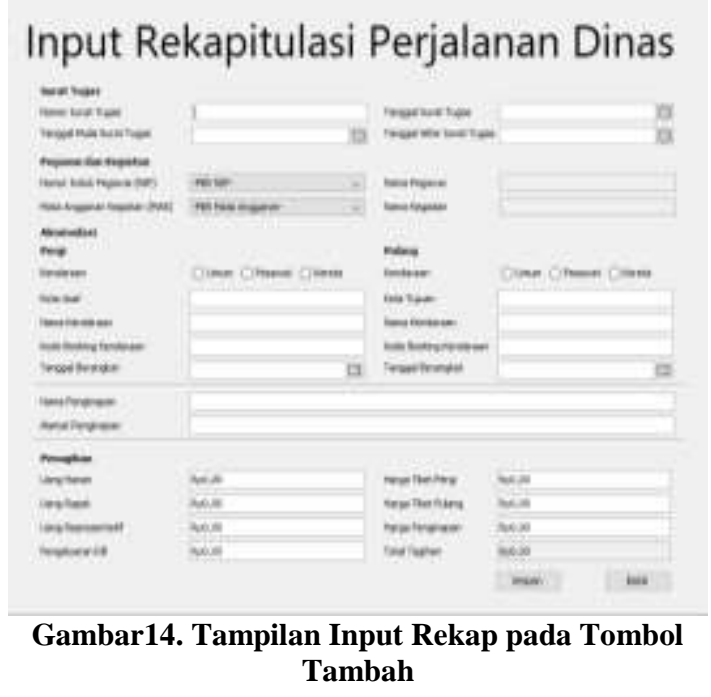

Gambar 11 merupakan tampilan isian input rekapitulasi perjalanan dinas berdasar berkas yang diterima dari pegawai setelah melakukan perjalanan dinas dimana terdapat isian kolom tagihan sudah terjumlah otomatis dengan mata uang Indonesia yaitu rupiah.

Tampilan Keluaran Sistem Aplikasi

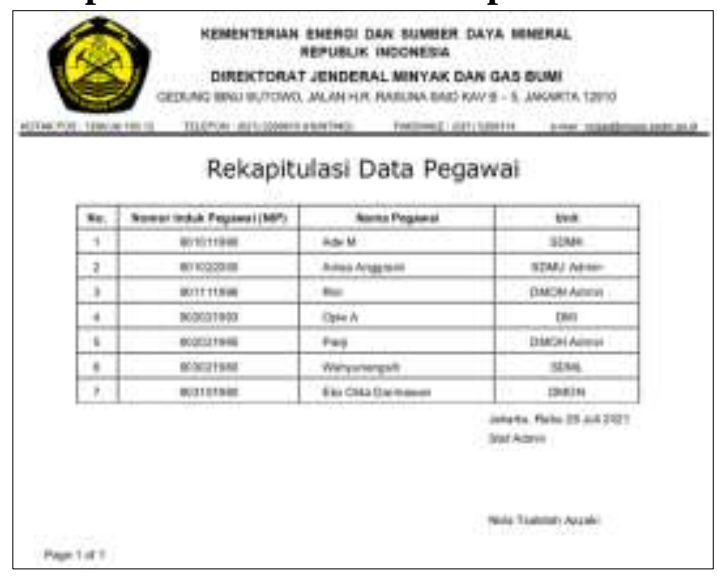

Gambar15. Tampilan Laporan Data Pegawai

Gambar 15 merupakan bentuk laporan dari data pegawai yang dicetak oleh staf admin setiap ada permintaan data kemudian diberikan kepada bagian keuangan. 


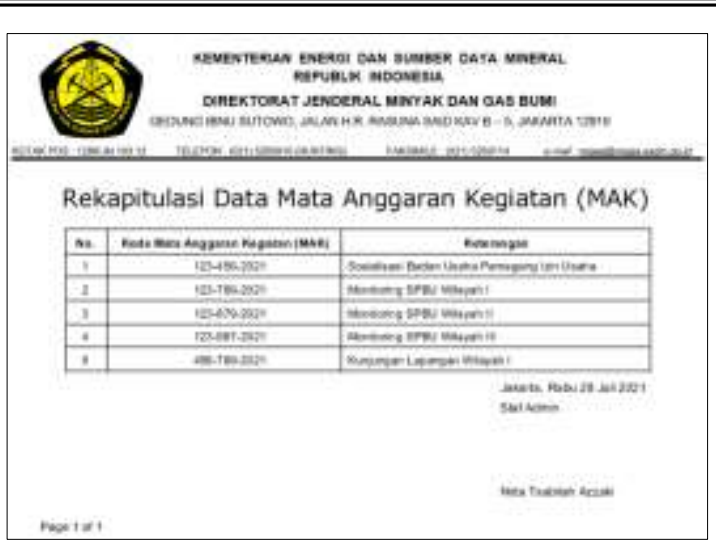

Gambar16. Tampilan Laporan Data MAK

Gambar 16 merupakan bentuk laporan dari data MAK yang dicetak oleh staf admin setiap ada permintaan data kemudian diberikan kepada bagian keuangan.

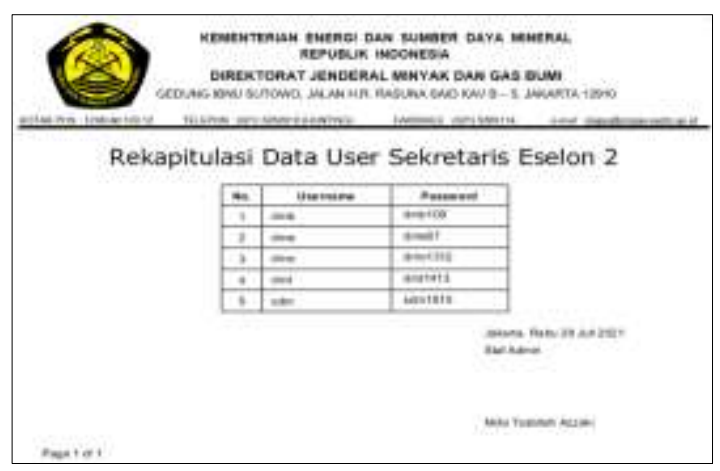

Gambar17. Tampilan Laporan Data User Sekretaris Eselon 2

Gambar 17 merupakan bentuk laporan dari data user sekretaris eselon 2 yang dicetak oleh staf admin setiap ada permintaan data kemudian diberikan kepada bagian keuangan.

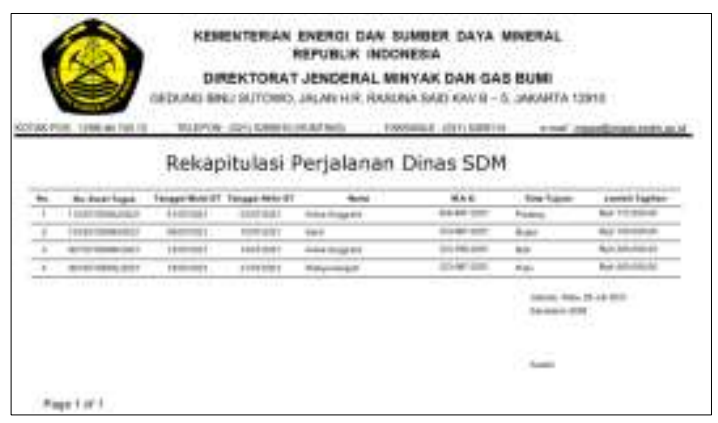

Gambar18. Tampilan Laporan Rekapitulasi Perjalanan Dinas per Eselon 2

Gambar 18 merupakan bentuk laporan dari data rekapitulasi perjalanan dinas per eselon 2 yang dicetak oleh sekretaris eselon 2 setiap tahun kemudian diberikan kepada bagian keuangan.

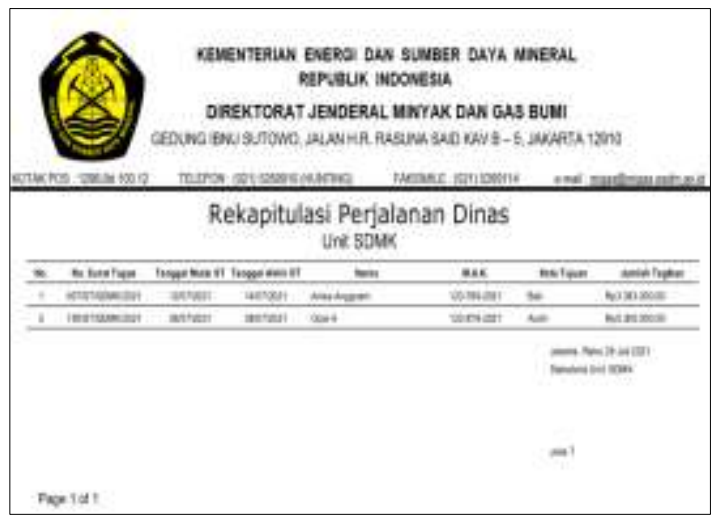

Gambar19. Tampilan Laporan Rekapitulasi Perjalanan Dinas per Unit Eselon 3

Gambar 19 merupakan bentuk laporan dari data rekapitulasi perjalanan dinas per unit eselon 3 yang dicetak oleh staf unit eselon 3 setiap tahun kemudian diberikan kepada bagian keuangan.

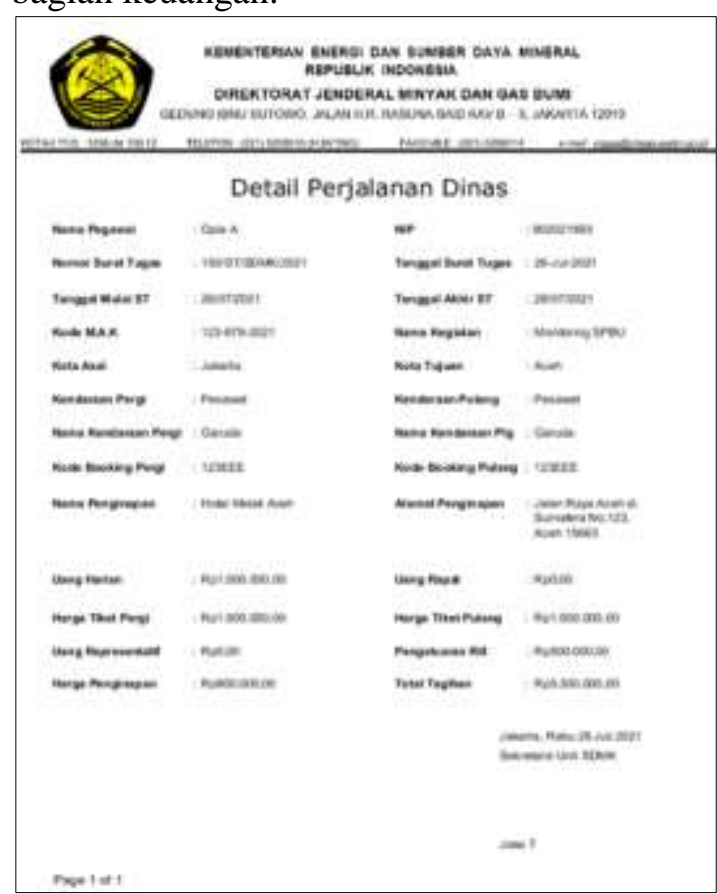

Gambar20. Tampilan Laporan Detail Perjalanan Dinas

Gambar 20 merupakan bentuk laporan detail perjalanan dinas pegawai yang datanya diambil dari data rekapitulasi perjalanan dinas per unit eselon 3 dan dicetak oleh staf unit eselon 3 setiap tahun kemudian diberikan kepada bagian keuangan.

\section{SIMPULAN DAN SARAN}

Simpulan penelitian serta pembuatan aplikasi rekapitulasi perjalanan dinas yang dapat diambil, yaitu sebagai berikut:

1. Sistem aplikasi ini dibuat dengan bahasa pemrograman java dengan editor NetBeans 
8.2 IDE dan tersimpan menggunakan database $M y S Q L$.

2. Sistem aplikasi ini dapat memberikan kemudahan dan mempercepat pencarian data dengan tepat dan akurat serta pengadministrasi mempunyai format rekapitulasi perjalanan dinas yang sudah ditetapkan dengan hanya mengisi form pada aplikasi ini.

3. Dengan adanya sistem aplikasi ini, dapat memberikan solusi dalam rekapitulasi perjalanan dinas pegawai dimana pengadministrasi melakukan rekapitulasi saat perjalanan dinas sudah selesai dengan lebih teliti dan tidak terburu-buru.

Dari hasil penelitian yang telah dilakukan, baik dalam hal penelitian maupun pengerjaan serta pembuatan aplikasi rekapitulasi perjalanan dinas terdapat beberapa saran:

1. Diharapkan aplikasi ini dapat up to date dengan seiring berkembangnya teknologi untuk membantu pengadministrasi Direktorat Jenderal Migas dalam menangani rekapitulasi perjalanan dinas pegawai setiap harinya.

2. Pengguna diharapkan untuk memperhatikan kekurangan dan kelemahan aplikasi ini, agar dapat segera dicari penyelesaian masalahnya.

3. Perlu perawatan dan pengembangan lebih lanjut agar program ini dapat memberikan manfaat yang lebih baik dan maksimal.

\section{DAFTAR PUSTAKA}

Andraswari, D. L., \& Sunoto, I. (2020). Sistem Seleksi Obat Dan Alat Kesehatan Fast Moving Pada Apotek Guardian Fatmawati. Semnas Ristek (Seminar ..., 408-414.

Asropudin, P. (2013). Kamus Teknologi Informasi Komunikasi. Titian Ilmu.

Fathansyah. (2012). Basis Data. Informatika Bandung.

Hamdani, A. U. (2015). Pemodelan Sistem Informasi Administrasi Proyek Desain Interior Studi Kasus: PT. Wang Interior Jakarta. SISFO, 05(03), 182.

Lubis, A. (2016). Basis Data Dasar. Deepublish.

Nadeak, B., Parulian, A., Pristiwanto, \& Siregar, S. R. (2016). Perancangan Aplikasi Pembelajaran Internet Dengan Menggunakan Metode Computer Based Instruction. Jurnal Riset Komputer (JURIKOM), 3, 54.

Nugroho, A. S. (2017). Analisis dan Perancangan Sistem Informasi. Trans Tekno.

Salim, \& Haidir. (2019). Penelitian Pendidikan: Metode, Pendekatan, dan Jenis. Kencana.

Sugiyono. (2016). Metode Penelitian Kuantitatif, Kualitatif, dan $R \& D$. PT Alfabet.

Wijaya, K. M. (2016). Pengertian CD (Context Diagram) dan DFD (Data Flow Diagram). 